\title{
Ewing's Sarcoma of Frontal Bone: A Rare Case
}

\author{
Rajneesh Misra ${ }^{1}$ Sushil Kumar ${ }^{1}$ Rohan Sinha' Sandeep Sharma \\ ${ }^{1}$ Department of Neurosurgery, St. Stephen's Hospital, Delhi, India \\ Address for correspondence Rajneesh Misra, MS, MCh, \\ FRCSEd, St. Stephen's Hospital, Tiz Hazari, Delhi 110054, India \\ (e-mail: misra_rajneesh@yahoo.com).
}

Indian J Neurosurg 2019;8:139-141
Abstract
Keywords
- primary Ewing's sarcoma
- round cell tumor
- frontoparietal bone

Primary Ewing's sarcoma arising from frontal bone is rare. We report a case of 17-yearold boy with painless swelling in the frontoparietal region. Computed tomography showed destruction of bone and an enhancing extradural mass. The patient underwent wide excision combined with radio and chemotherapy. Histopathology revealed it to be round cell sarcoma, and immunohistochemistry confirmed it to be Ewing's sarcoma.

\section{Introduction}

Primary Ewing's sarcoma arising from the skull is very rare although it is the second most common tumor in the children. The skull is involved in less than $2 \%$ cases, and it most commonly originates from bone and soft tissues of the extremities and pelvis. ${ }^{1,2}$ Recently we came across a large painless primary Ewing's sarcoma arising from frontoparietal bone with good survival, hence being reported.

\section{Case Report}

A 17-year-old man presented with a swelling in the frontal region of 6 months duration, which started increasing in size during the previous 3 months. There was no history of pain in the swelling, headache, vomiting, or fever. There was no history of loss of weight or appetite. There was no history of trauma. On examination, the patient was fully conscious, alert, and oriented with no focal neurologic deficits. The fundus was normal. There was a $15-\times 16$-cm-sized swelling in the bifrontal region. Swelling was firm in overall consistency and a soft portion in the posterolateral area. Overlying skin was free. There was no visible pulsation or bruit. Swelling was nontender, and the temperature over it was normal.

Three-dimensional computed tomographic (3D CT) reconstruction image revealed multiple osteolytic areas ( $\mathbf{- F i g . 1 A}$ ). Contrast CT revealed an enhancing osteolytic soft tissue mass in the frontoparietal area ( - Fig. 1B-D). Fine-needle aspiration cytology (FNAC) was reported to be a round cell sarcoma. At surgery, the lesion was found to be soft, fleshy, mildly vascular, and easily separable from the dura. Wide excision of the tumor and surrounding bone was done, and healthy dura was seen peripheral to the tumor. Dura was not excised. There was no involvement of the superior sagittal sinus. Postoperative 3D CT reconstruction showed wide craniectomy (-Fig. 1E). Histopathology revealed it to be round cell sarcoma, and immunohistochemistry confirmed it to be Ewing's sarcoma. Immunohistochemistry revealed positivity for vimentin, $\mathrm{CD} 3$, CD20, and CD60 in some cells. The cells were negative for HMB-45 and S100. The patient was given local radiation of $45 \mathrm{~Gy}$ and chemotherapy consisting of vincristine, cyclophosphamide, and cisplatin, ifosfamide, etoposide, and Adriamycin. He is currently doing well at 60 months follow-up. A hard underlying membrane formed in the area of craniectomy after approximately 3 years. The patient was offered cranioplasty on various occasions at follow-up, but he refused. Repeated positron emission tomography (PET) scan during follow-up has revealed no evidence of recurrence of tumor ( - Fig. 1F).

\section{Discussion}

Primary Ewing's sarcoma is a highly malignant bone tumor. It is a member of Ewing's sarcoma family of tumors (ESFT), others being primitive neuroectodermal tumor, Askin's tumor, and extraosseous Ewing's sarcoma. These tumors are more commonly seen in young and adolescents and are characterized by small and round cells.,4

Our patient presented with swelling without any symptoms and signs of raised intracranial pressure or neurologic involvement. The temporal bone is most commonly involved followed by parietal, occipital, sphenoid, and ethmoid in that order. $^{5}$

Plain X-ray usually shows bone destruction, with irregular poorly defined margins. CT usually shows isodense received

November 24, 2018

accepted

December 28, 2018

published online

August 13, 2019
DOI https://doi.org/

$10.1055 / \mathrm{s}-0039-1695088$

ISSN 2277-954X.
C2019 Neurological Surgeons'

Society of India
License terms

(®) (1) $\Theta$ 

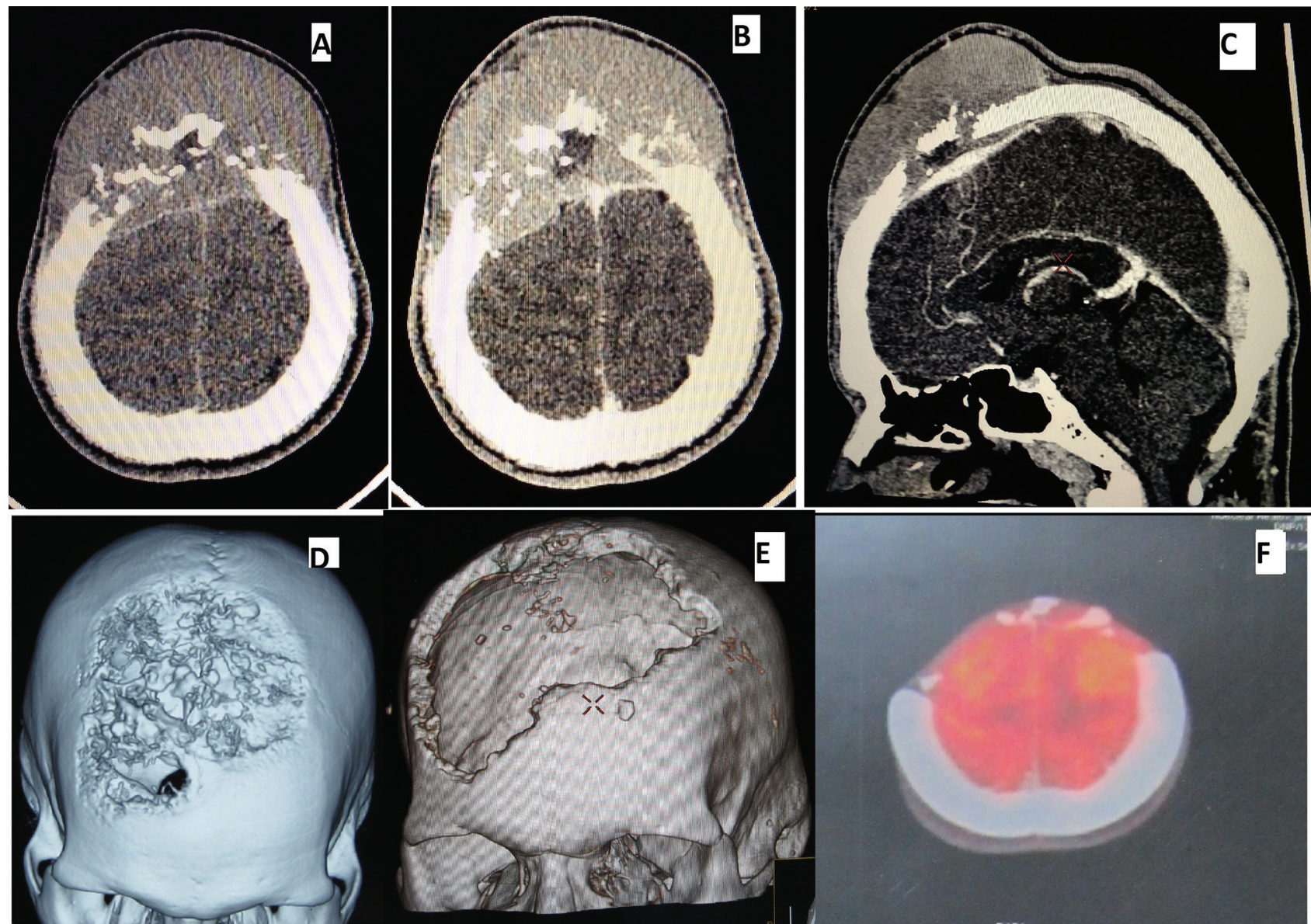

Fig. 1 (A, B) Preoperative plain and post contrast images showing bone destruction with soft tissue homogenous enhancing mass. (C) CT lateral view showing patent sagittal sinus and epidural soft tissue mass with intact dura. (D) Preoperative 3D CT reconstruction image showing multiple osteolytic areas. (E) Postoperative 3D CT reconstruction showing wide craniectomy. (F) PET scan showing no recurrence at operative margins.

lesion with marked heterogonous enhancement. Magnetic resonance imaging (MRI) shows well-defined lobulated extra-axial mass lesion with mixed intensity signals on both $\mathrm{T} 1$ and $\mathrm{T} 2 \mathrm{~W}$ images. ${ }^{6} \mathrm{FNAC}$ and biopsy are essential to reach a diagnosis, but definitive diagnosis is reached by immunohistochemistry. Differential diagnosis of such lesion includes metastatic neuroblastoma, rhabdomyosarcoma, osteosarcoma, and meningioma.

Treatment of Ewing's sarcoma is multimodal. It includes surgery, radiotherapy, and repeated courses of chemotherapy consisting of ifosfamide, cisplatin, etoposide, and Adriamycin. Our patient is symptom free for the past 60 months, and the repeat PET scan has been negative for local or distant recurrence. Primary Ewing's sarcoma of the skull has been known to metastasize to the lungs and bone. Duration of symptoms of longer than 6 months, absence of fever or systemic symptoms, peripheral location and absence of metastasis, leukocyte count of $<7,000 / \mathrm{dL}$, and lymphocyte count of $<2,000 / \mathrm{dL}$ indicate a good outcome. ${ }^{7-9}$

Primary Ewing's sarcoma of the skull vault has relatively good prognosis because it can be totally or subtotally excised with wide margins. However, sarcomas arising from the skull base by involving vital structures preclude surgical excision.
To conclude, primary cranial Ewing's sarcoma should be considered in the differential diagnosis in adolescence with tumor involving the skull with destruction of bone and presence of extracranial soft tissue mass.

\section{Conflict of Interest}

The authors declare no conflict of interest.

\section{References}

1 Tsokos M. Peripheral primitive neuroectodermal tumors. Diagnosis, classification, and prognosis. Perspect Pediatr Pathol 1992;16:27-98

2 Steinbok P, Flodmark O, Norman MG, Chan KW, Fryer CJ. Primary Ewing's sarcoma of the base of the skull. Neurosurgery 1986;19(1):104-107

3 Angervall L, Enzinger FM. Extraskeletal neoplasm resembling Ewing's sarcoma. Cancer 1975;36(1):240-251

4 Jaffe R, Santamaria M, Yunis EJ, et al. The neuroectodermal tumor of bone. Am J Surg Pathol 1984;8(12):885-898

5 Singh P, Jain M, Singh DP, Kalra N, Khandelwal N, Suri S. MR findings of primary Ewing's sarcoma of greater wing of sphenoid. Australas Radiol 2002;46(4):409-411

6 Srihari K, Bindu PM, Ramreddy KV, Moorthy RS, Reddy GR. A rare case of atypical primary Ewing's sarcoma of occipital bone. J Evid Based Med Healthcare 2016;3(56):2934-2936 
7 Mishra HB, Haran RP, Joseph T, Chandi SM. Primary Ewing's sarcoma of the skull. A report of two cases. Br. J Neurosurg 1993;7(6):683-686 (Case Rep)

8 Kuzeyli K, Aktürk F, Reis A, et al. Primary Ewing's sarcoma of the temporal bone with intracranial, extracranial and intraorbital extension. Case report. Neurosurg Rev 1997;20(2):132-134
9 Erol FS, Ozveren MF, Ozercan IH, Topsakal C, Akdemir I. Primary Ewing's sarcoma of the occipital bone-case report. Neurol Med Chir (Tokyo) 2001;41(4):206-209 